\title{
Application of Cognitive Modelling for Operation Improvement of Retail Chain Management System
}

\author{
Oksana Dankeieva ${ }^{1}$, Nataliia Solomianiuk ${ }^{1}$, Larysa Strashynska ${ }^{1}$, \\ Nataliia Fiedotova ${ }^{1}$, Yuliia Soloviova ${ }^{1}$, Viktor Koval ${ }^{2}$ \\ ${ }^{1}$ National University of Food Technologies Volodymyrska Street, 68, Kyiv, Ukraine \\ ${ }^{2}$ Odessa Institute of Trade and Economics of Kyiv National University of Trade and Economics, \\ Inglezi 6, Odesa, Ukraine
}

\begin{abstract}
The purpose of the study is to implement cognitive modelling of the retail chain management system to ensure the effectiveness of management decisions in order to implement structural changes in its activities. It is determined that the organization of retail chain management is more effective due to provided principles of a systematic approach which are applied. Therefore, using the concept of Balanced Scorecard (BSC) in this study, which reflects the interaction and interdependence of structural units, which is feasible, we propose it to further search for development scenarios for the retail chain management. The article presents a sequence of cognitive modelling, which consists of seven main stages. Drogerie - format management system of retail chains has been chosen since it has recently been standing out by its popularity with consumers among other formats, as an object for the study. The results of this study can be useful for enterprises and organizations with complex systems
\end{abstract}

DOI: $10.18421 /$ TEM101-45

https://doi.org/10.18421/TEM101-45

Corresponding author: Viktor Koval,

Odessa Institute of Trade and Economics of Kyiv National University of Trade and Economics, Inglezi 6, Odesa, Ukraine.

Email: victor-koval@ukr.net

Received: 17 December 2020.

Revised: 20 January 2021.

Accepted: 26 January 2021.

Published: 27 February 2021.

(c))BY-NC-ND 2021 Viktor Koval et al; published by UIKTEN. This work is licensed under the Creative Commons Attribution-NonCommercial-NoDerivs 4.0 License.

The article is published with Open Access at www.temjournal.com that are characterized by hierarchical, network relationships between subsystems or where random processes take place.

Keywords - cognitive map, concept models, balanced scorecard, development scenarios, retail chains.

\section{Introduction}

Sustainable development of retail chains requires managers to constantly improve existing methods of managing retail facilities to ensure a competitive advantage in the market environment. Cognitive modelling is considered to be one of the newest directions of the modern theory of managerial decision-making, recognized among scientific methods of management efficiency improvement.

A significant advantage of cognitive modelling in the management system of retail enterprises, which are characterized by a large number of elements, relationships and interactions between them, the complexity of the structure, volatility, and presence of both quantitative and qualitative characteristics - is the ability to analyse and predict as a whole and its components, without losing a connection between them. The relevance of the study of the problem of retail chain management system in the application of cognitive modelling means that there is an opportunity: to solve a set of theoretical and practical problems purposely and coherently; not only to generate alternative solutions for the management of a complex system or adaptation to it but also to assess the consequences of decisions; reduce the risk of the human factor and increase the effectiveness of management decisions. The article aim is to implement cognitive modelling of the retail chain management system to ensure the effectiveness of management decisions and the introduction of structural changes in its operation. 


\section{Literature Review}

The definition of "cognitive" (Latin "cognitio" knowledge, the cognitive process of the human mind) was borrowed from psychology in the second half of the twentieth century, regarding the information processing, logical thinking, imagination, decision making, etc.

The most famous representative of this approach is Atkinson [1], who identified numerous structural components (blocks) of cognitive and executive processes - memory. It is also worth mentioning the work of Anderson [2], Axelrod [3], Baars [4], who first proposed using cognitive maps in order to analyze situations and make decisions with a high degree of uncertainty.

Development of the computer became a significant incentive for the further application of cognitive modelling. Technology reduced the time spent on alternatives, helped to visualise the studied model, increased the accuracy of calculations and reliability of the analysis. Currently, some researchers actively use the cognitive approach in their scientific and practical research, among them: Sharifi [5], Pérez-López, González-López, Rodríguez-Ariza [6], Litau [7]. However, the possibility of applying the methodology of retail chain management based on cognitive modelling has not been studied yet.

In general, modelling is the replacement of one object with another to obtain information about the most important properties of the original object using a model object. The simulation is based on the theory of similarity, according to which absolute similarity is possible only when replacing one object with the same another [7], [8].

Cognitive modelling is a tool of cognition designed to solve a set of low-structured system problems: determining the object of study, conducting an expert procedure for selecting factors, determining the type, strength and nature of the influence of selected factors, building a cognitive map, forecasting, decision making, adaptability, self-organization [8]. The purpose of cognitive modelling is to predict the development of the system, its management, to determine the possibilities of its adaptation to the outer environment.

\section{Methodology}

According to the goal of the study, a set of general and specific methods of scientific knowledge have been applied, such as:

- analysis and synthesis, cognitive modelling (to find the best scenarios for retail network management improvement);
- graphic method (to visualize information, its grouping, comparison, and generalization).

Analysing the theoretical and methodological basis of cognitive modelling, a certain sequence of its implementation has been found [9]:

1. Establishing the purpose and objectives of the study.

2. Analysing the level of complexity of the situation that needs to be clarified concerning the goal. Scientists usually collect, systematize, analyse data in terms of quantitative and qualitative information about the object of management and its environment, as well as determine the conditions and limitations at this point.

3. Identification of the main factors influencing the development of the management situation.

4. Determining the dependency between factors due to causality (creation of a cognitive map in the form of a directed graph).

5. Examination of the power of the interaction of various factors. For this purpose, both mathematical models are used, which describe some precisely identified quantitative relationships between factors, and the subjective ideas of the expert on the formalization of qualitative relationships between factors. In stages 3-5, the final cognitive model of the system is built, which is depicted as a functional graph.

6. Verification of the sufficiency of the cognitive model for a real situation.

7. Determining possible options with the help of a cognitive model for the development of the situation (system), identifying ways, and mechanisms of influence to achieve the desired results, prevention of undesirable consequences by creating management strategies. Defining desired directions and factors for changing processes trends. Selecting a set of measures (a set of control factors), determining their possible and desired impact (specific and practical application of the cognitive model) are explained by [6], [9], [10], [11].

The studied literature on cognitive modelling [8], [9], [10] showed that most authors consider the model in the form of a cognitive map, which formally has the form of a directed graph, the vertices of which are factors, and the edges are the relationship between them (1) [11].

$$
G=\langle V, E\rangle,
$$

where $V$ is the set of vertices, the vertices $V i \in V(i$ $=1,2 \ldots k)$ are elements of the studied system strategic goals; $E$ is the set of edges, the edges are $E$ $(i, j=1,2 \ldots N)$ reflect the relation between the vertices $V i$ and $V j$. 
Given directed graph reflects the influence of factors taking into account the weights of the edge Wij established by experts. The weights of the edges can be established on the basis of the functional dependence (if any), as well as the coefficient bij from the linear regression dependence of factors type such as $y j=a+b i j x i[12]$.

Thus, the direct (quantitative) and indirect (qualitative) influence of factors on the indicators selected for efficiency assessment have been taken into account.

This allows to more fully describing the problem area and the effect of the implementation of certain measures. Studies have also shown that factors can affect each other [6], [9], [10], [12]. Two elements of the system are depicted in the scheme as separate points - vertices $V i$ and $V j$ if the element $V i$ is connected with the element $V j$ by a causal relation: $V i V j$, where $V i$ is the cause, $V j$ is the consequence.

To study the management system, retail chains of the Drogerie-format were chosen, which was determined by its popularity with consumers among other retail formats: first, their stores are located "near the house". According to a study held by [13], $56 \%$ of people choose stores closer to their home, $46 \%$ - prefer to shop quickly. Secondly, thanks to its range, which is easily optimized for the needs of the local consumer, moderate pricing, loyalty programs, etc., makes them important. The study involved 18 experts from the chain of selected format, who were grouped into three groups according to the following requirements: the first group of experts included 6 senior sellers of selected companies who have been working in this chain for at least three years and have the total experience of more than five years in trade; the second group of experts included 6 administrators of trading rooms with experience of administrative work over three years with higher education in economics; the third group consisted of 6 marketers with higher education in marketing management or more than five years of experience in this or a similar position.

The experts were asked to fill out a questionnaire that determined the degree of the judgment of each expert on the given questions. The study has shown the consistency of experts' opinions by calculating the Kendall concordance coefficient. The coefficient was equal to 0.98 , which testified to the almost complete consistency of experts' opinions. Scenarios for the development of the management system in the retail chain "BROCARD" were modelled based on the obtained data.

\section{Results and Discussion}

The key to the success of the network in a market full of threats and dangers is a purposeful management organization based on a systematic approach. Research emphasizes that the category "system" means a whole set of mutually dependent parts [14]. In general, any set of interacting objects can be identified as a systemic formation, i.e. a system. Thus, the vast majority of systems, especially economic ones, are complex because they are: characterized by a large number of elements and internal connections, their heterogeneity and diversity, the performance of many functions, as well as the content of subsystems; hierarchical - due to the order of components in order of importance; open because there is a constant information exchange with the environment; dynamic - with the inevitable transition of processes, indicators, characteristics, etc. from one state to another; homeostatic - through efforts to maintain integrity, achieve their own goals and the ability to influence certain processes of the environment, etc.

Therefore, based on a systematic approach to retail chain management, to model development scenarios, the concept of Balanced Scorecard (BSC) was chosen Kaplan, Norton [15], [16], which reflects the interaction and interdependence of four perspectives: "Finance", "Clients", "Internal Business Processes" and "Training and Development". According to the procedure of cognitive modelling, the primary task is to establish the purpose and objectives of the study. Since the guaranteed indicator of the functioning of all structural units of retail networks is the indicator of profitability, the strategic goal setting has been "Increase in profits compared to the previous period." The most important goals corresponding to the main prospects of the Balanced Scorecard (BSC) were also identified (Table 1).

It was expedient to supplement the goals of prospects with the following initial indicators measurability and recognition. Measurability indicates a quantitative or qualitative indicator, and recognition indicates a value in the retail chain management system. Then, according to the method of cognitive modelling, the control vertices were chosen, through which control actions will be submitted, the vertices of the perspective "Internal business processes"; target peaks, a given change of which has to be achieved - the peaks of the perspective "Finance"; indicator peaks that characterize the development of economic processes of the model - the peaks of prospects "Clients" and "Training and Development". To search for system development scenarios for making more effective management decisions in the activities of retail chains, the following task set has been defined to achieve the following strategic goals [14], [17], [18]:

- construct a graph and determine the vertices, as well as their edges; 
- determine the distinction of vertices in the concept of the model;

- investigate the relation of the vertices and their edges of each of the prospects to determine the stability/instability of the system;

- explore the relationship between prospects in terms of sustainability;
- in the case where the studied system is resistant to influence (excitation), conduct pulse modelling, which should reflect the possible scenario of the situation;

- analyse the results obtained to select a more effective management decision.

Table 1. Concept Models

\begin{tabular}{|c|c|c|c|c|}
\hline Perspectives & Goals - meaning of vertices & $\begin{array}{l}\text { Abbreviation } \\
\text { for vertices }\end{array}$ & $\begin{array}{l}\text { Characteristic } \\
\text { of vertices }\end{array}$ & Measurability \\
\hline \multirow{3}{*}{ Finance $(\mathrm{F})$} & 1.Increase in profit compared to previous period & PR & Goal & Quantitative \\
\hline & 2.Extention of the structure of activity & $S E$ & Goal & Quantitative \\
\hline & 3. Sales growth & $S G$ & Goal & Quantitative \\
\hline \multirow{5}{*}{ Clients (C) } & 1.Increase in the number of consumers & $C N I$ & Indicator & Quantitative \\
\hline & $\begin{array}{l}\text { 2.Increase in the number of customers who make } \\
\text { repeat purchases }\end{array}$ & CRPI & Indicator & Quantitative \\
\hline & 3.Improving online sales & OSI & Indicator & Quantitative \\
\hline & 4.Personalisation & $P S$ & Indicator & Qualitative \\
\hline & 5.Focus on the "profitable" consumer & $P C F$ & Indicator & Qualitative \\
\hline \multirow{5}{*}{$\begin{array}{c}\text { Internal } \\
\text { business } \\
\text { processes } \\
\text { (IBP) }\end{array}$} & 1.Expanding the product range & PRE & Management & Quantitative \\
\hline & $\begin{array}{l}\text { 2.Emotional component increase for better } \\
\text { perception of store visits }\end{array}$ & $E$ & Management & Qualitative \\
\hline & 3.Increasing chain brand-loyalty & $L$ & Management & Qualitative \\
\hline & 4.Creating a positive (image) for the chain & $B$ & Management & Qualitative \\
\hline & 5. Supply optimization Client Orientation & $\mathrm{CO}$ & Management & Qualitative \\
\hline \multirow{5}{*}{$\begin{array}{l}\text { Training and } \\
\text { Development } \\
\text { (TD) }\end{array}$} & 1.Reducing staff turnover & $K$ & Indicator & Qualitative \\
\hline & 2.Stuff motivation & $M$ & Indicator & Qualitative \\
\hline & 3.Staff training system development & $S T$ & Indicator & Qualitative \\
\hline & 4. Increasing the internal focus on the customer & $F C$ & Indicator & Qualitative \\
\hline & 5. Job satisfaction increase & $J S$ & Indicator & Qualitative \\
\hline
\end{tabular}

As already emphasized, modern retail chains are open economic systems that, reaching these goals, interact closely with each other and the external environment. According to the requirements of cognitive modelling in the construction of the relationship graph - these are the edges coming from the top, which characterizes the corresponding goal of the perspective to achieve the strategic goal (Figure 1).

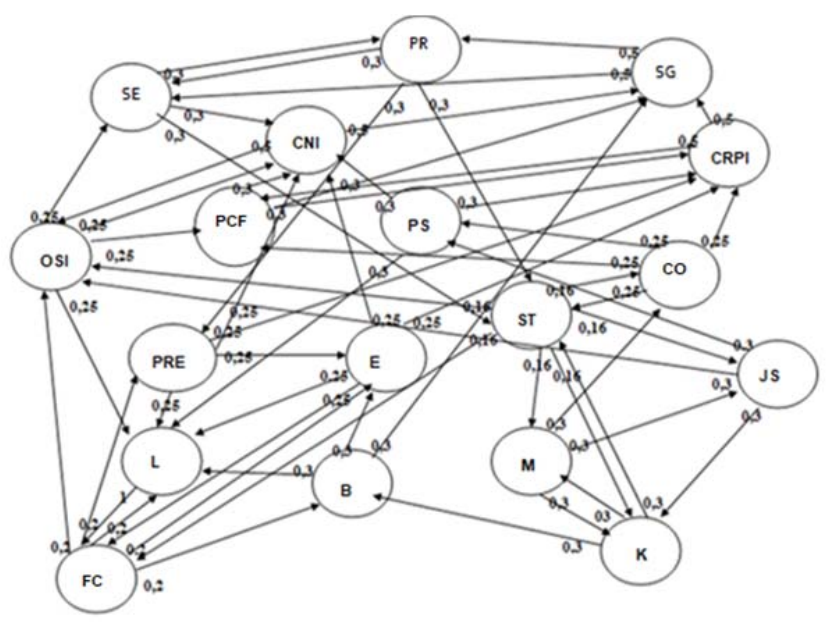

Figure 1. Cognitive Map OF The Retail Network Management System
Note: PR - Profit; SE - Extension of the structure of activity; $S G$ - Sales Growth; CNI - Consumers Number Increase; CRPIIncrease in the number of customers who make repeat purchases; OSI - Online sales improvement; PS Personalization; PCF-Focus on the "profitable" consumer; $\mathrm{CO}$ - Client Optimization; PRE - Expanding the product range; $E$ Emotional component increase for better perception of store visits; $L$ - brand-loyalty increase; $B$-Creating a positive image for the chain; $K$-Reducing staff turnover; $M$ - Staff Motivation; ST - Staff training system development; FC - Increasing the internal focus on the customer; JS - Job satisfaction increase.

To determine the importance of the value of the vertices of the graph, an expert group of employees of the network "BROCARD" was involved along with a calculation of Kendall concordance coefficient of experts' agreement -0.74 , which means a high extent of agreement.

According to the rules of the survey, the experts were offered a Likert rating scale, where it was necessary to set scores from 4 - the highest score, to 1 - the lowest score. The average assessment of experts is the value of the goal.

According to the rules of graph theory, the fulfilment of one goal depends on the achievement of others. Therefore, each target vertex is related to several other goal vertices, forming a transition and probabilities (Table 2). The connections between the ribs should have only positive consequences because the fulfilment of one goal will have a positive effect 
on the achievement of others. Thus, the value of the edge that connects to the vertices will show the impact on the aspired goal.

The obtained indicators provide an opportunity to investigate the relationship between the vertices and their edges to determine the stability in individual perspectives and the entire system of the retail trade chain. Given the fact that retail networks have to make management decisions in conditions of uncertainty, the use of probabilistic approaches are considered by researchers [8], [9], [12] are the most rational. Due to the comparative simplicity and clarity of the mathematical apparatus, the high probability and accuracy of the obtained solutions, Markov's chain theory deserves special attention.

They describe the behaviour of complex systems, which are characterized by hierarchical, network relationships between subsystems or subsystems where random processes occur. In order to calculate the numerical parameters that will characterize this randomness, it is necessary to build a probabilistic model of the phenomenon, which will take into account probabilistic factors.

Table 2. Relationship of Vertices of Cognitive Map of Retail Chain Management System

\begin{tabular}{|l|c|c|c|c|c|c|c|c|c|c|c|c|c|c|c|c|c|}
\hline & PR & SE & SG & CNI & CRPI & OSI & PS & PCF & PRE & E & L & B & CO & K & M & ST & FC \\
\hline PR & 0 & 0 & 0 & 0 & 0 & 0 & 0 & 0 & 0,34 & 0 & 0 & 0 & 0 & 0 & 0 & 0,33 & 0 \\
\hline SE & 0,3 & 0 & 0 & 0 & 0,33 & 0 & 0 & 0 & 0 & 0 & 0 & 0 & 0 & 0 & 0 & 0,33 & 0 \\
\hline SG & 0,5 & 1 & 0 & 0 & 0 & 0 & 0 & 0 & 0 & 0 & 0 & 0 & 0 & 0 & 0 & 0 & 0 \\
\hline $\boldsymbol{C N I}$ & 0 & 0 & 0,5 & 0 & 0 & 0,5 & 0 & 0 & 0 & 0 & 0 & 0 & 0 & 0 & 0 & 0 & 0 \\
\hline $\boldsymbol{C R P I}$ & 0 & 0 & 0,5 & 0 & 0 & 0 & 0 & 0,5 & 0 & 0 & 0 & 0 & 0 & 0 & 0 & 0 & 0 \\
\hline $\boldsymbol{O S I}$ & 0 & 0 & 0 & 0,3 & 0 & 0 & 0 & 0,25 & 0 & 0 & 0,25 & 0 & 0 & 0 & 0 & 0 & 0 \\
\hline $\boldsymbol{P S}$ & 0 & 0 & 0 & 0,3 & 0,33 & 0 & 0 & 0 & 0 & 0 & 0,34 & 0 & 0 & 0 & 0 & 0 & 0 \\
\hline $\boldsymbol{P C F}$ & 0 & 0 & 0,33 & 0,3 & 0,33 & 0 & 0 & 0 & 0 & 0 & 0 & 0 & 0 & 0 & 0 & 0 & 0 \\
\hline $\boldsymbol{P R E}$ & 0 & 0 & 0 & 0,3 & 0,25 & 0 & 0 & 0 & 0 & 0,25 & 0,25 & 0 & 0 & 0 & 0 & 0 & 0 \\
\hline $\boldsymbol{E}$ & 0 & 0 & 0 & 0,3 & 0,25 & 0 & 0 & 0 & 0 & 0 & 0,25 & 0 & 0,25 & 0 & 0 & 0 & 0 \\
\hline $\boldsymbol{L}$ & 0 & & & 0 & 0 & 0 & 0 & 0 & 0 & 0 & 0 & 0 & 1 & 0 & 0 & 0 & 0 \\
\hline $\boldsymbol{B}$ & 0 & 0 & 0,33 & 0 & 0 & 0 & 0 & 0 & 0 & 0,33 & 0,34 & 0 & 0 & 0 & 0 & 0 & 0 \\
\hline CO & 0 & 0 & 0 & 0 & 0 & 0,2 & 0 & 0 & 0,2 & 0,2 & 0,2 & 0,2 & 0 & 0 & 0 & 0 & 0 \\
\hline $\boldsymbol{K}$ & 0 & 0 & 0 & 0 & 0 & 0 & 0 & 0 & 0 & 0 & 0 & 0,33 & 0 & 0 & 0,34 & 0,33 & 0 \\
\hline $\boldsymbol{M}$ & 0 & 0 & 0 & 0 & 0 & 0 & 0 & 0 & 0 & 0 & 0 & 0 & 0 & 0,33 & 0 & 0 & 0,33 \\
\hline $\boldsymbol{S T}$ & 0 & 0 & 0 & 0 & 0 & 0,16 & 0 & 0 & 0 & 0 & 0 & 0 & 0,16 & 0,16 & 0,16 & 0 & 0,16 \\
\hline $\boldsymbol{F C}$ & 0 & 0 & 0 & 0 & 0,25 & 0 & 0,25 & 0,25 & 0 & 0 & 0 & 0 & 0 & 0 & 0 & 0,25 & 0 \\
\hline JS & 0 & 0 & 0 & 0 & 0 & 0 & 0,33 & 0,34 & 0 & 0 & 0 & 0 & 0 & 0,33 & 0 & 0 & 0 \\
\hline
\end{tabular}

Note: PR - Profit; SE - Extension of the structure of activity; SG - Sales Growth; CNI-Consumers Number Increase; CRPIIncrease in the number of customers who make repeat purchases; OSI - Online sales improvement; PS - Personalization; PCFFocus on the "profitable" consumer; CO - Client Optimization; PRE - Expanding the product range; E - Emotional component increase for better perception of store visits; $L$ - brand-loyalty increase; $B$-Creating a positive image for the chain; $K-R e d u c i n g$ staff turnover; $M$ - Staff Motivation; ST - Staff training system development; FC-Increasing the internal focus on the customer; JS Job satisfaction increase.

Researching complex systems that develop under the influence of random factors, it is possible to assume that the system - $S$ (in our case - a separate perspective), defined by this graph, consistently passes through discrete-time intervals from one state to another, forming many states: $S_{1}, S_{2}, \ldots, S_{n}$, Transitions of the system from state to state are possible only at fixed moments of time $t: t_{1}, t_{2}, \ldots$, $t_{n}$.

Thus, a random process that occurs in the system is a function of an integer argument. According to Wentzel [19], if for each step the probability of transition from any state to any other state does not depend on when and how the system came to such a state, and then the sequence of events is a Markov chain.
According to the theory, the Markov chain [19] is homogeneous, i.e. the transitions of the system from state to state are described by transient probabilities, which are constant values $P_{i j}=P$.

To simplify the analysis of the model, investigation of the relationship between the vertices and their edges for each of the perspectives will be carried out and, if necessary, their stability in perspectives established [20].

Since the top of the perspective "Finance" is the target factor of its implementation depends on the following perspectives: "Clients", "Internal Business Processes", "Training and Development". Figure 2 shows the approximate graph of the BSC perspective "Customers". 


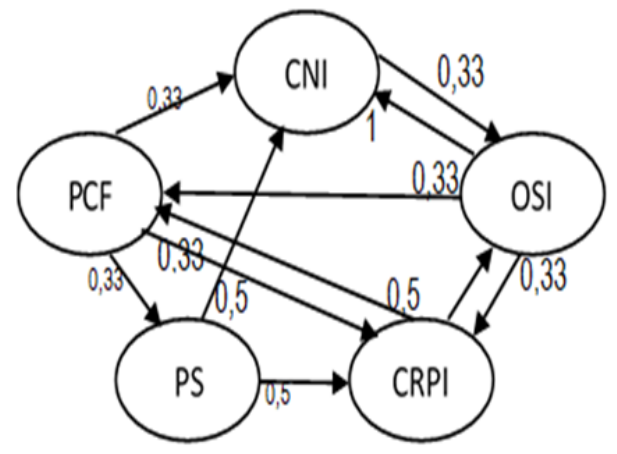

Note: CNI - Consumers Number Increase; CRPI - Increase in the number of customers who make repeat purchases; OSI Online sales improvement; PS - Personalization; PCF- Focus on the "profitable" consumer.

Figure 2. Directed Graph of BSC Perspective "Clients"

According to the initial information, the transition probabilities are given by the following weights, where $P i j$ is the probability of transition in one step from the state $S i$ to the state $S j$. In our case, the element $P$ is the weight of the edge (see Figure 2), coming from the specified vertex-target:

$\begin{array}{ccccc}\mathrm{P} 11=0 & \mathrm{P} 12=0 & \mathrm{P} 13=0 & \mathrm{P} 14=1 & \mathrm{P} 15=0 \\ \mathrm{P} 21=0 & \mathrm{P} 22=0 & \mathrm{P} 23=0,5 & \mathrm{P} 24=0 & \mathrm{P} 25=0,5 \\ \mathrm{P} 31=0,33 & \mathrm{P} 32=0,33 & \mathrm{P} 33=0 & \mathrm{P} 34=0 & \mathrm{P} 35=0,33 \\ \mathrm{P} 41=0,5 & \mathrm{P} 42=0,5 & \mathrm{P} 43=0 & \mathrm{P} 44=0 & \mathrm{P} 45=0 \\ \mathrm{P} 51=0,33 & \mathrm{P} 52=0,33 & \mathrm{P} 53=0 & \mathrm{P} 54=0,33 & \mathrm{P} 55=0\end{array}$

Then the transition probability matrix $P$ will take the form:

$\begin{array}{ccccc}0 & 0 & 0,33 & 0,5 & 0,33 \\ 0 & 0 & 0,33 & 0,5 & 0,33 \\ 1 & 0,5 & 0 & 0 & 0 \\ 0 & 0 & 0 & 0 & 0,33 \\ 0 & 0,5 & 0,33 & 0 & 0\end{array}$

The initial state of the system is set by a vectorcolumn, which is formed by expert evaluation and has passed the procedure of coordination, prospects "Clients". The experts had to determine the weight of the components of the perspective so that in the end the amount equals 1 .

$$
p(0)=\left(\begin{array}{c}
0,3 \\
0,12 \\
0,14 \\
0,3 \\
0,14
\end{array}\right)
$$

An equation that describes the state of the system in $S$ at $k$-moment of time is described by matrix equations in recurrent form.

$$
p(k)=P^{T} \cdot p(k-1),(k=1,2, \ldots, n),
$$

where the matrix transposed relative to the matrix $R$.

The results of calculations by equation (4) using MS Excel are shown below in Figure 3.

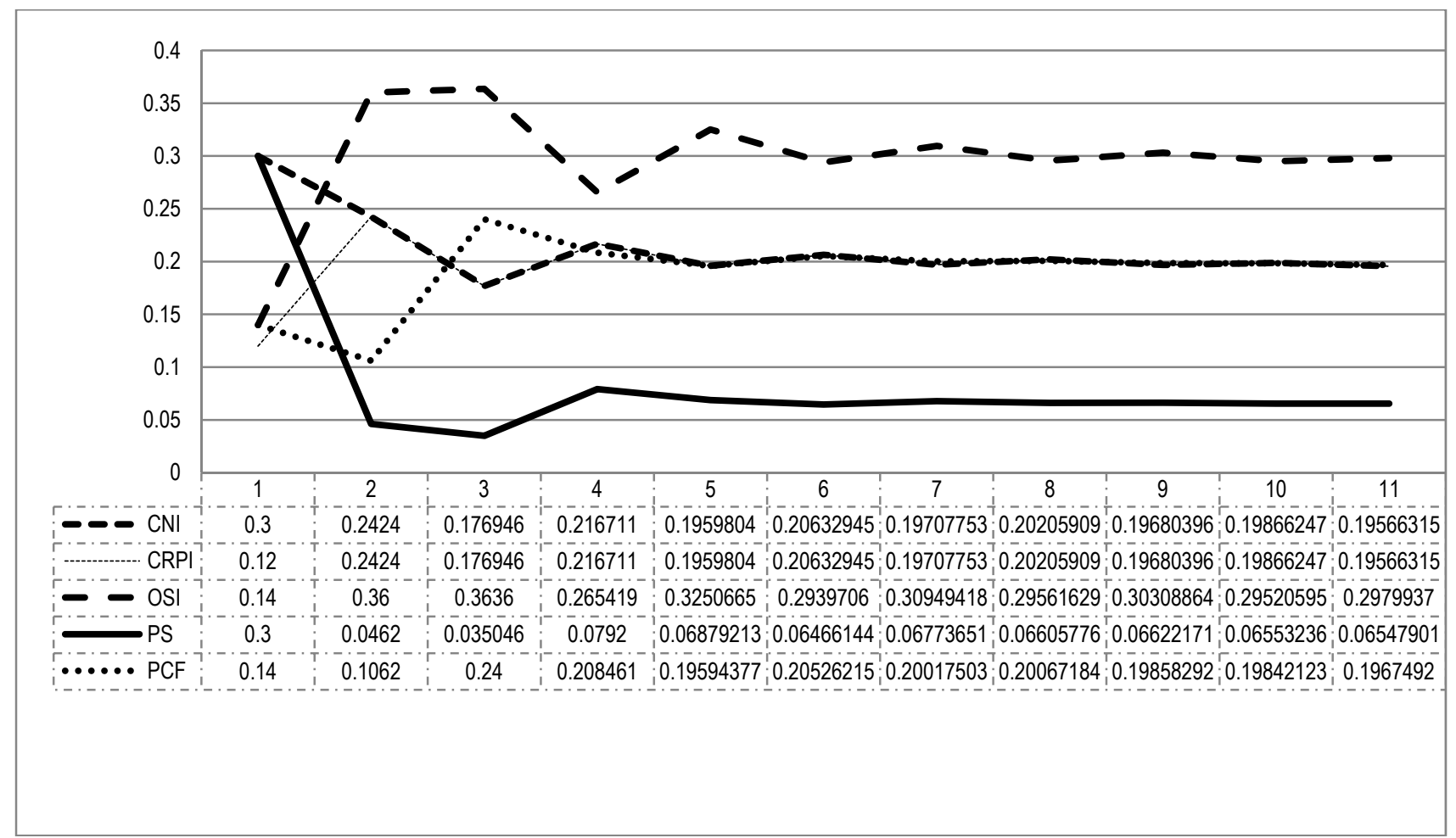

Note: CNI - Consumers Number Increase; CRPI - Increase in the number of customers who make repeat purchases; OSI - Online sales improvement; PS - Personalization; PCF-Focus on the "profitable" consumer.

Figure 3. Results of Calculations for Perspective "Clients" 
Therefore, the analysis of graphs shows that the system over time, the probability of reaching the resistance to impact (stationary mode), when:

$$
p(\infty)=\left(\begin{array}{c}
0,196 \\
0,196 \\
0,298 \\
0,0655 \\
0,197
\end{array}\right)
$$

These calculations of interactions and weights of their vertices the perspective "Customers" mean that starting from the 3rd step, the stable development of this perspective will be subject to improved online sales (0.298), targeting the "profitable" consumer (0.197) will increase, however as at the initial stage, the promising components of increasing the number of consumers $(0.3)$ and their personalization $(0.3)$ were identified.

Similarly, the stable development of prospects "Internal Business Processes" and "Training and Development" is defined. The calculations are given in Figure 4 and Figure 5.

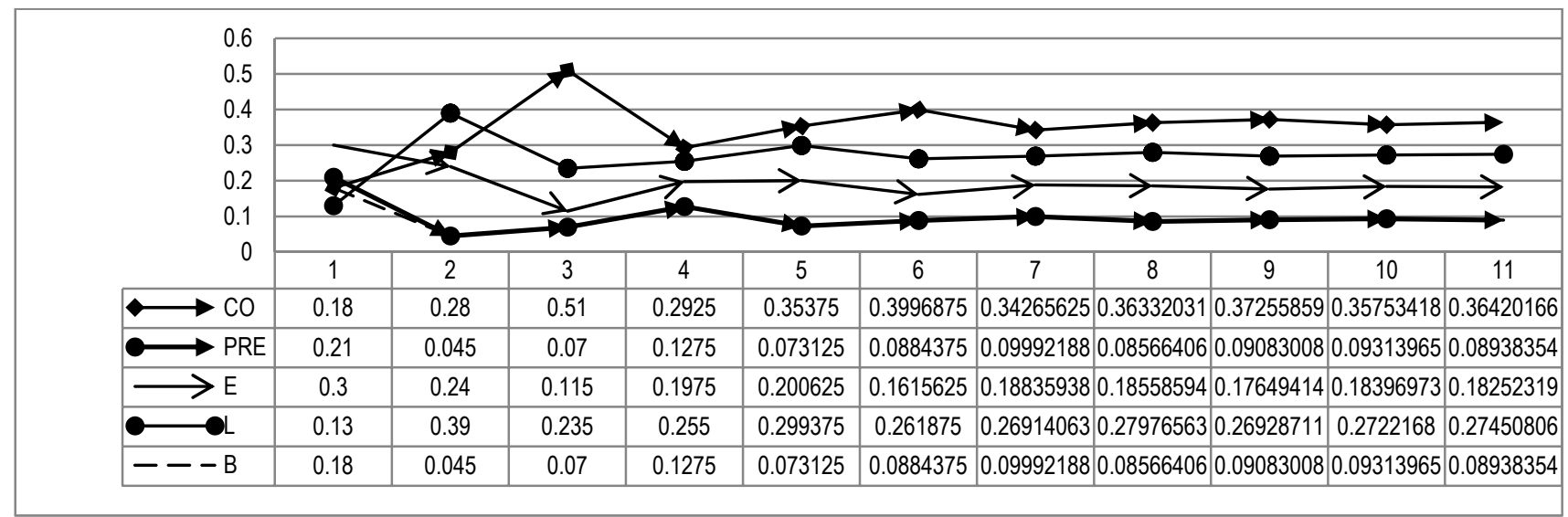

Note: $C O$ - Client Optimization; PRE - Expanding the product range; E - Emotional component increase for better perception of store visits; $L$ - brand-loyalty increase; $B$ - Creating a positive image for the chain.

\section{Figure 4. Results of Calculations for Perspective "Internal Business Processes"}

Thus, if at the initial consideration the experts considered the development of this perspective farreaching with the proper development of the emotional (0.3) component, the calculations of interactions and weights of their peaks of the perspective "Internal Business Processes" showed that stable network development will be achieved by increasing the value of the component optimization of work with suppliers (0.364) and improvement of measures to increase consumer loyalty $(0.275)$.
The construction of the initial vector of the last perspective "Learning and Development", according to experts, allowed to determine the same prospects for all components, as the degree of employee satisfaction depends on meeting the goals of all the above prospects and achieving this main strategic goal [21], [22], [23]. Table 5 shows the results of establishing stability in the vertices and their edges depending on the 4 th step of the experiment.

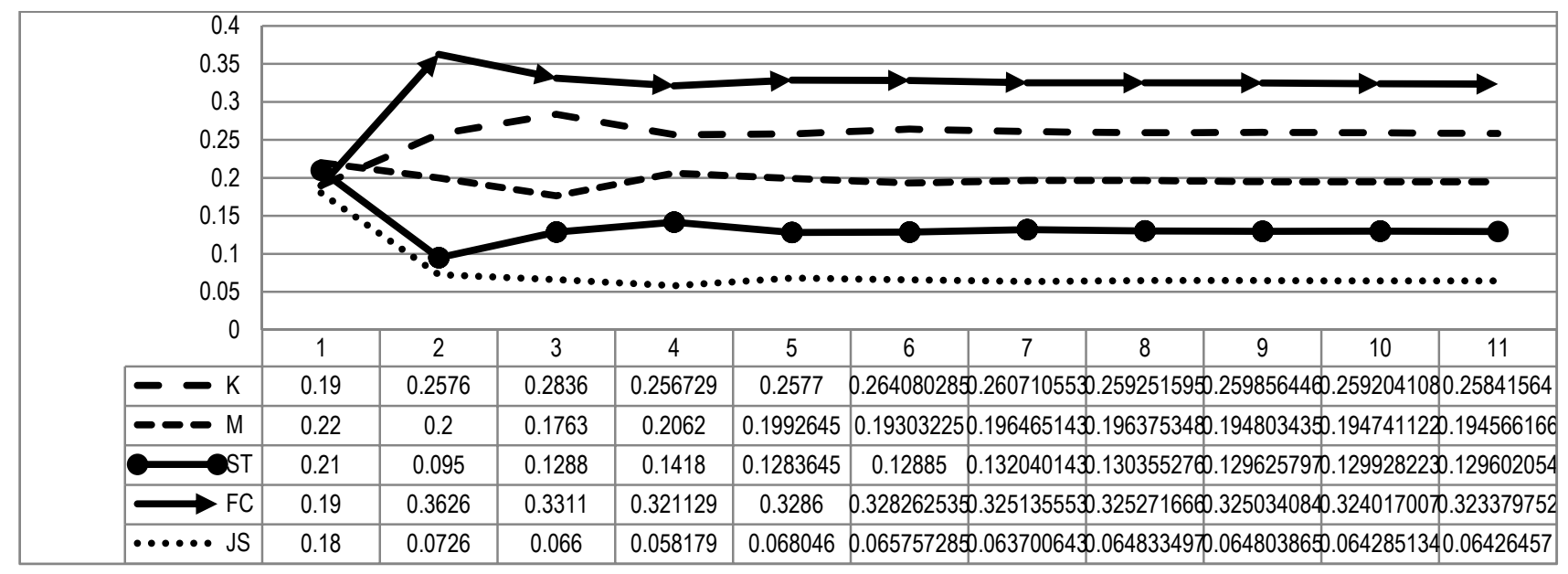

Note: $K$ - Reducing staff turnover; $M$ - Staff Motivation; ST - Staff training system development; FC - Increasing the internal focus on the customer; JS - Job satisfaction increase.

Figure 5. Results of Calculations for Perspective "Training and Development" 
Therefore, stable development in this perspective will be subject to proper development and implementation of new systems to increase internal consumer orientation (0.323).

The stability of the whole model is represented by graph (Figure 6) and the stable development of all prospects in a similar scenario is established, where the initial vector is expert assessments (Figure 7).

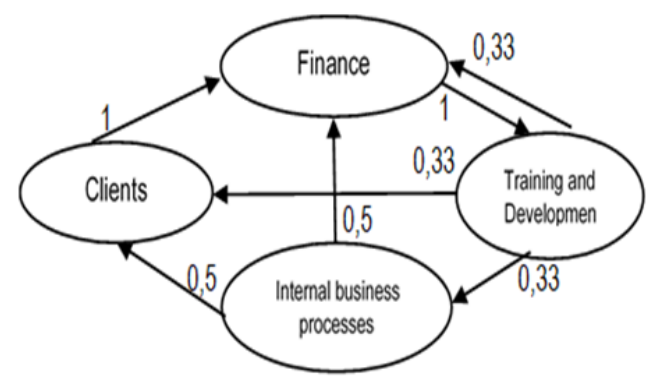

Figure 6. Graph of BSC Prospects
The obtained calculations showed (Figure 7) that the retail network is developing steadily in the 4th step. Next, according to the plan of the task of formalizing the qualitative links between the factors were set to achieve the goal. The plan of the experiment consisted of the successful introduction of disturbances to the top of the component perspective "Internal business processes": first "Expansion of the range of goods", then - to the top "Optimization of work with suppliers".

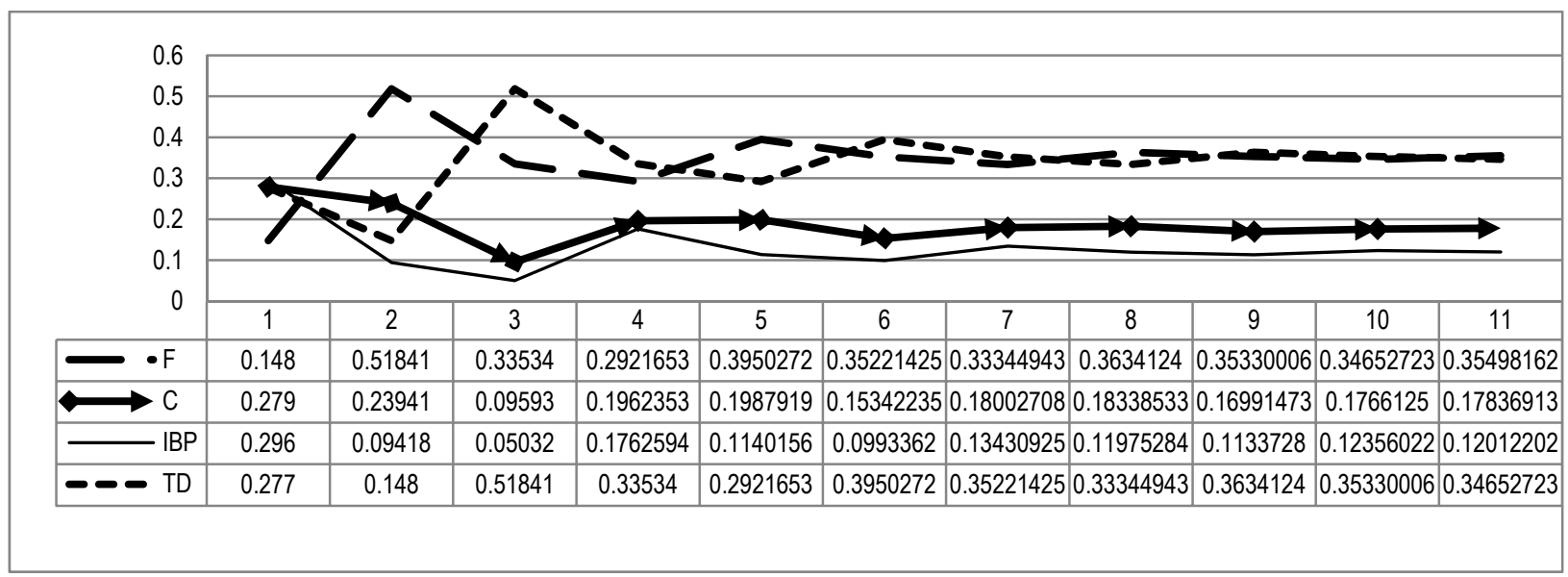

Note: F-Finance; $C$-Clients; IBP - Internal business procedures; TD - Training and Development

\section{Figure 7. Results of Calculations for BSC Prospects}

According to the theory [9] modelling of pulse processes occurs according to the formula:

$$
\mathrm{x}_{i}(n+1)=\mathrm{x}_{i}\left(\text { п) } \sum_{j=1}^{k-1} f_{i j} P_{j}(n)+Q_{i}(n)\right.
$$

where $x_{i}(n)$ - value of impulse in the point $i$ in the previous moment (pace of modelling) $(n)$,

$x_{i}(n+1)-$ value of impulse in the point $i$ at the interesting for the researcher moment $(n+1)$;

$f_{i j}$ - the momentum conversion factor in the initial stages of modelling is considered $f_{i j}=1$;

$P_{j}(n)$ - the value of the pulse in the vertices adjacent to the vertex $\mathrm{i}$;

$Q i(n)$ - vector of perturbations and control influences entering the top and moment $(n)$.

While adding $Q_{i}(n)$ the question "What happens at the moment $(n+1)$ if?" is investigated.

The set of implementations of impulse processes is called "development scenario" and indicates possible trends in situations.

The situation in pulse simulation is characterized by a list of all $Q i$ values of $X$ in each of its cycles. The calculation formula obtained from [9], [24], and
[25] determines the changes in the parameters of the vertices by the equations:

$X_{n}=X_{n-1}+\mathrm{AR}_{n-1}+Q_{n-i}$

$R_{n}=A^{n-1} Q_{0}+A^{n-1} Q_{1}+\ldots+\mathrm{AQ}_{n-2}+\mathrm{IQ}_{n-1}$

Having made a perturbation at the top of the graph by $20 \%$, corresponding to the control factor "Optimization of work with suppliers", an increase in the target factor "Profit" is observed by more than $10 \%$. For greater clarity, Figure 4 shows an element of the graph with vertices in which the corresponding indicators were significantly increased.

Having made a perturbation at the top of the graph by $20 \%$, corresponding to the control factor "Expansion of the product range", an increase in the target factor "Profit" to $15 \%$ is observed (Figure 8 ).

Thus, the results of the experiments showed that the significant control factors are the factors "Optimization of work with suppliers" and "Expansion of the range", to which management needs to pay priority attention. Thus, cognitive modelling and its implementation illustrate the 
dependence of network performance on many factors and confirms that in order to obtain sound management decisions to stabilize the state of such a system need to form subjective models of problems, analysis which helps to increase the level of sound recommendations needed to support management decisions [26], [27], and [28].

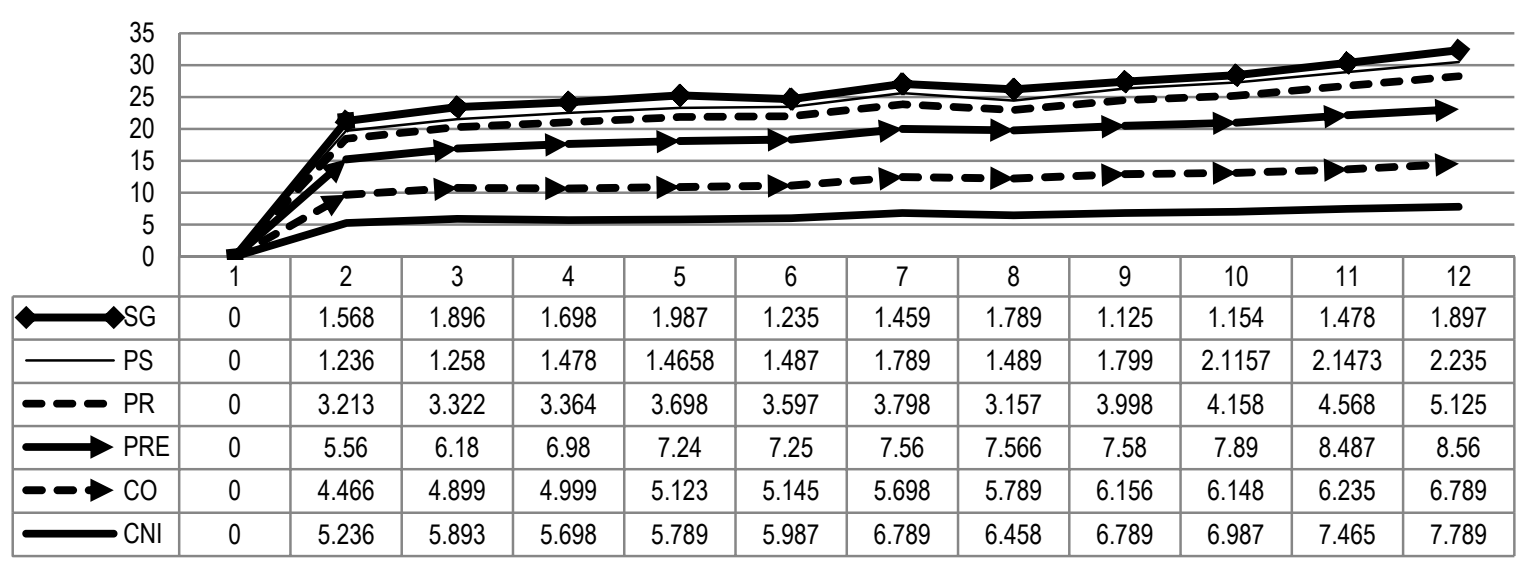

Note: PR - Profit; PRE - Expanding the product range; фi CNI - Consumers Number Increase; PS - Personalization; SG - Sales Growth; $\mathrm{CO}$ - Client Optimization.

\section{Figure 8. Results of Experiment with Increasing Control Factor "Expansion of the Product Range"}

The obtained simulation results show that the situational approach in the form of cognitive models provides an opportunity to provide effective structural transformations in the management system of retail networks of Drogerie-format [29], [30], [31].

\section{Conclusions}

Using modern management models requires the use of powerful analytical tools to assess the performance of the management system, which should be a significant basis for more effective management decisions. The use of a balanced scorecard allows us to specify the goals and strategies of the management system in terms of the overall strategy of the retail network.

This will determine the strategic guidelines for the development of the network management system, depending on the development of all its components, as well as to identify the most promising to increase the efficiency of its operation.

The issue of modelling scenario development in retail network management systems is extremely complex and multifaceted.

Due to the insufficient level of its development in both methodological and applied aspects, it is advisable to use mathematical models and use known analytical tools based on software packages. The search for scenarios is modelled on the example of a specific retail network, which allows determining the most effective consequences of development and making more effective management decisions based on them.

We will focus on modelling the development of scenarios in retail network management systems using other quantitative and qualitative indicators that will ensure the efficiency of economic activity in a changing business environment.

\section{References}

[1]. Atkinson, R. C., Herrnstein, R. J., Lindzey, G., \& Luce, R. D. (Eds.). (1988). Stevens' handbook of experimental psychology. (Vols. 1). New York: Wiley.

[2]. Anderson, J. R. (1990). Cognitive psychology and its implications (3rd ed.). New York: Freeman.

[3]. Axelrod, R. (1976). The Structure of Decision: Cognitive Maps of Political Elites. United States: Princeton University Press.

[4]. Baars, B. J. (1993). A cognitive theory of consciousness. Cambridge University Press.

[5]. Sharifi, S. S., \& Esfidani, M. R. (2014). The impacts of relationship marketing on cognitive dissonance, satisfaction, and loyalty: The mediating role of trust and cognitive dissonance. International Journal of Retail \& Distribution Management, 42(6), 553-575.

[6]. Pérez-López, M. C., González-López, M. J., \& Rodríguez-Ariza, L. (2019). Applying the social cognitive model of career self-management to the entrepreneurial career decision: The role of exploratory and coping adaptive behaviours. Journal of Vocational Behavior, 112, 255-269.

[7]. Litau, E. (2018, August). Entrepreneurship and economic growth: A look from the perspective of cognitive economics. In Proceedings of the 2018 9th International Conference on E-business, Management and Economics (pp. 143-147).

[8]. Nicolás, C., Rubio, A., \& Fernández-Laviada, A. (2018). Cognitive determinants of social entrepreneurship: Variations according to the degree of economic development. Journal of Social Entrepreneurship, 9(2), 154-168. 
[9]. Udell, M., Stehel, V., Kliestik, T., Kliestikova, J., \& Durana, P. (2019). Towards a smart automated society: Cognitive technologies, knowledge production, and economic growth. Economics, Management and Financial Markets, 14(1), 44-49.

[10]. Ginis, L. A. (2020, November). Methodological basis of simulation and cognitive modelling technology of socio-economic systems. In Journal of Physics: Conference Series (Vol. 1661, No. 1, p. 012035). IOP Publishing. https://doi.org/10.1088/1742-6596/1661/1/012035

[11]. Firsova, A. A., Makarova, E. L., \& Tugusheva, R. R. (2020). Institutional management elaboration through cognitive modeling of the balanced sustainable development of regional innovation systems. Journal of Open Innovation: Technology, Market, and Complexity, 6(2), 32. http://doi.org/10.3390/joitmc6020032

[12]. Gorelova, G., \& Badwan, N. (2019). Cognitive Modeling for the Intellectual System of Supporting Decision Making on Regulating Reproduction and Accumulation of Financial Capital. International Research Journal of Finance and Economics, 175, 7082.

[13]. Nielsen (2018). Retail Measurement. Retrieved from: https://www.nielsen.com/eu/en/solutions.html. [accessed: 12 November 2020].

[14]. Rousseau D, Billingham J, Wilby JM, Blachfellner S (2016) In search of general systems theory. Systema 4(1), 76-92

[15]. Kaplan, R. S., \& Norton, D. P. (1996). Using the balanced scorecard as a strategic management system. Harvard Business Review, 74(1), 75-85.

[16]. Kaplan, R. S., \& Norton, D. P. (2001). Strategyfocused organization: How balanced scorecard companies thrive in the new business environment. Boston: Harvard Business School Press.

[17]. Kostetska, K., Khumarova, N., Umanska, Y., Shmygol, N., \& Koval, V. (2020). Institutional qualities of inclusive environmental management in sustainable economic development. Management Systems in Production Engineering, 28(1), 15-22. https://doi.org/10.2478/mspe-2020-0003

[18]. Arsawan, I. W. E., Koval, V., Rajiani, I., Rustiarini, N. W., Supartha, W. G., \& Suryantini, N. P. S. (2020). Leveraging knowledge sharing and innovation culture into SMEs sustainable competitive advantage. International Journal of Productivity and Performance Management. https://doi.org/10.1108/IJPPM-04-2020-0192
[19]. Wentzel, E.S. (1972). Issledovanie operacij [Operations research]. Moscow: Soviet Radio. [in Russian].

[20]. Nouri, F. A., Nikabadi, M. S., \& Olfat, L. (2019). Developing the framework of sustainable service supply chain balanced scorecard (SSSC BSC). International Journal of Productivity and Performance Management, 68(1), 148-170.

[21]. Wood, M. D., Bostrom, A., Bridges, T., \& Linkov, I. (2012). Cognitive mapping tools: review and risk management needs. Risk Analysis: An International Journal, 32(8), 1333-1348.

[22]. Gardner, H. (1985). The mind's new science: A history of the cognitive revolution. New York: Basic Books.

[23]. Arsawan, I. W. E., Sanjaya, I. B., Putra, I. K. M., \& Sukarta, I. W. (2018). The effect of expatriate knowledge transfer on subsidiaries' performance: a moderating role of absorptive capacity. In Journal of Physics: Conference Series (Vol. 953, No. 1, p. 012082). IOP Publishing.

[24]. Osherson, D.N. y H. Lasnik, Eds. (1990): Language. An Invitation to Cognitive Science, Vol. 1. The MIT Press: Cambridge (MA).

[25]. Roseman, I. J. (1984). Cognitive determinants of emotions: A structural theory. In P. Shaver (Ed.). Review of personality and social psychology: Vol. 5, Emotions. Relationships, And Health. Beverly Hills, CA: Sage.

[26]. Eden, C. (1988). Cognitive mapping. European Journal of Operational Research, 36(1), 1-13.

[27]. Ayers, J. B., \& Odegaard, M. A. (2017). Retail supply chain management. CRC Press.

[28]. Fernie, J., \& Sparks, L. (Eds.). (2018). Logistics and retail management: emerging issues and new challenges in the retail supply chain. Kogan page publishers.

[29]. Gandhi, A., Shaikh, A., \& Sheorey, P. (2017). Impact of supply chain management practices on firm performance. International Journal of Retail \& Distribution Management, 45(4), 366-384.

[30]. Krasyuk, I. A., Krymov, S. M., Medvedeva, Y., Chernisheva, A. M., \& Lashko, S. I. (2017). Marketing Management in Retail Chains. International Journal of Applied Business and Economic Research, 15(12), 83-91.

[31]. Ekinci, E., \& Baykasoğlu, A. (2019). Complexity and performance measurement for retail supply chains. Industrial Management \& Data Systems, 119(4), 719-742. 